\title{
Bank versus Venture Capital ${ }^{*}$
}

\author{
Masako Ueda ${ }^{\dagger}$ \\ Universitat Pompeu Fabra
}

November 2000

\begin{abstract}
Why do some start-up firms raise funds from banks and others from venture capitalists? To answer this question, I develop a model of start-up financing when intellectual property rights are not well protected. The upside of $\mathrm{VC}$ financing is that the $\mathrm{VC}$ understands the business better than a bank. The downside, however, is that the VC may steal the idea and use it himself. The results of the model are consistent with empirical regularities on start-up financing. The model implies that the characteristics of the firms financing from venture capitalists are low-collateral, high-growth and high-profitability. The model also suggests that the tighter protection of intellectual property rights contributes to the recent dramatic growth of the US venture capital industry.
\end{abstract}

${ }^{*}$ I would like to thank Franklin Allen, Gary Gorton, Boyan Jovanovic, Matthias Kahl, and Joshua Lerner for comments at an early stage of this paper. I also thank Giacinta Cestone, Matthew Ellman, Xavier Freixas, Thomas Hellmann, Holger Mueller, Javier Suarez, Lucy White, and the seminar participants at Universitat Autonoma de Barcelona (IAE), Universitet van Amsterdam, and the 2000 CEPR/Studienzentrum Gerzensee European Summer Symposium of Financial Markets for valuable discussion, and Frank Schmidt for helping to obtain the data.

${ }^{\dagger}$ Mailing Address: Masako Ueda, Departament d'Economia i Empresa, Universitat Pompeu Fabra, Ramon Trias Fargas, 25-27, 08005 Barcelona, Spain; Phone: +34(93)542-2578; Fax: +34(93)542-1746; E-mail: masako.ueda@econ.upf.es 


\section{Small Business Financing}

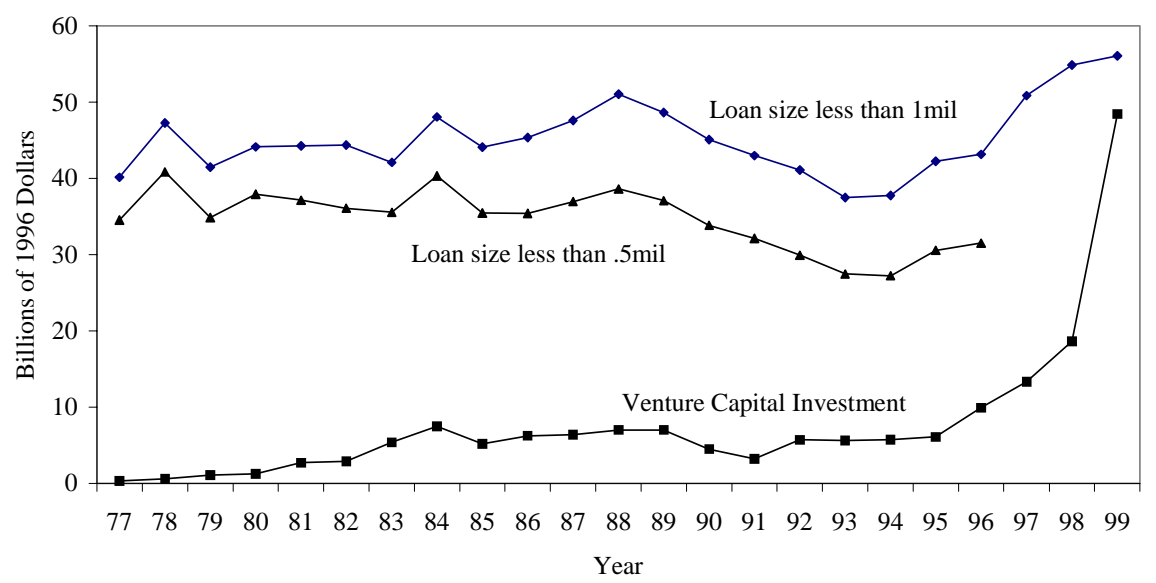

Figure 1:

Data Sources: The data on loans come from Survey of Terms of Bank Lending by Federal Reserve System. The data on venture capital come from National Venture Capital Association (NVCA). Loan size less than 1(.5) mil is the sum of commercial and industrial loan less than 1(.5) million dollars made by all US commercial banks in respective years. In 1997, Federal Reserve System changed the classification of loan category and size. As a consequence, the amounts of loan size less than .5mil and long-term loans are not reported here. Venture capital investment is the sum of investment made by the NVCA member venture capitalists.

\section{Introduction}

Venture capital industries have grown dramatically recent few years. In the "New Economy", venture capitalists are playing a crucial role in incubating new and small firms by supplying them with equity capital. It is difficult for such firms to access public financial markets owing to lack of reputation and therefore financial intermediaries have been the main sources of external funds for such firms. In contrast to the recent rapid growth of venture capital industries, traditional financial intermediaries such as commercial banks seem rather slow in meeting up with the financial needs of small and new firms. Figure 1 compares how much these two types of financiers have supplied small busi- 
nesses with funds in the US. The top two lines are proxies for the total amount of lending to small businesses. ${ }^{12}$ And the bottom line is the amount of venture capital investment in the US. As seen from this figure, the US venture capital industry experienced rapid growth twice. First, boosted by the clarification of the ERISA prudent man rule in 1979, the venture capital industry took off in the early 80s and maintained similar level of investment until 1995 except for the credit crunch in 1990 and $1991 .^{3}$ Second, the venture capital industry has been multiplied since 1995 and it is now about to exceed the amount of bank loans to small business.

To demonstrate the rapid growth of venture capital relative to bank, Figure 2 plots venture capital investment as a percentage of commercial and industrial loans each of that is less than 1 million dollars. The trend of venture capital investment is similar to that in Figure 1: the first boom is in the early 80 s and the second in the late 90s.

Venture capital is increasing its importance not only in supplying firms with funds but also in bringing the firms to public. For instance, in the first quarter of 2000, 75 venture capital backed firms went to IPO and this accounts for $53.8 \%$ of the total number of IPO. (April 10, 2000, Venture Economics)

\footnotetext{
${ }^{1}$ For comparison with venture capital investment, it would be more accurate to use the sum of lending amounts to small business rather than the sum of small size loans as large firms may also obtain small size loans. Nonetheless, the data on lending to small business are collected infrequently. (For instance, see National Survey of Small Business Finance by Board of Governors, Federal Reserve System.) Based on this survey, Berger and Udell (1998) report that in 1993, $36.27 \%$ of external funds for small businesses are originated from commercial banks, $3.57 \%$ from venture capital, and $15.3 \%$ from the other financial institutions such as finance companies.

${ }^{2}$ US Small Business Administration defined less-than- 250,000USD- loan as a proxy for small business lending until 1995 and increased the limit to 1million USD in 1996. Furthermore, Survey of Terms of Bank Lending does not divide the data on loan less than 250,000 USD. For this reason, I adopt the two cutoffs: .5million USD and 1million USD.

${ }^{3}$ Before 1979, most pension funds had refrained from investing in venture capital not to violate "prudent man rule" in the US. Department of Labor of the Employment Retirement Income Security Acts (ERISA). In 1978, the Department of Labor clarified venture capital as a possible investment target for pension funds and in 1979, this clarification was implemented. This clarification is considered to have made it substantially easier for venture capital to raise funds since each venture capital organization is typically small and does not have an own mean to raise a large amount of funds directly from original investors.

In the early 1990s, the U.S. economy experienced credit crunch. At this period, many of large institutional investors were troubled by their asset-quality problem and withdrew their funds from venture capital industries. (Fenn, Liang, and Prowse 1994)
} 
VC Investment/Commercial Loans less than $1 \mathrm{~m}$

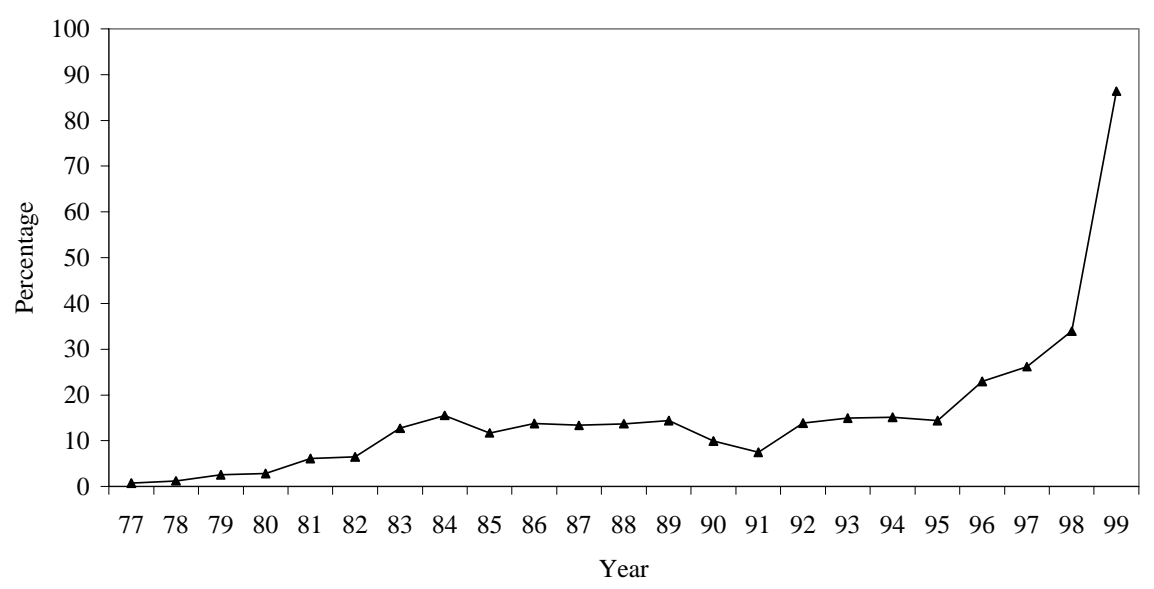

Figure 2:

Why did venture capital become so important compared to banks? To answer this question, I study the decision of an entrepreneur who chooses either a bank or a venture capitalist (VC) as the supplier of external funds. The model hinges on two assumptions. First, VC has the technological expertise that allows her to identify projects better than the bank. Second, this expertise also allows $\mathrm{VC}$ to undertake the projects without the original entrepreneur. Justifications for both assumptions are well-documented. First, VC companies typically specialize in a small group of industries. (Sahlman, 1990) This specialization presumably deepens the technical knowledge about the industries in which VC has been investing. The technological expertise obtained through the specialization presumably helps $\mathrm{VC}$ companies to articulate and identify possible difficulties to undertake and complete the projects. Hence, VC companies can presumably assess the profitability of the projects more accurately than a bank can. Second, evidence shows that VC-backed firms can continue the projects without the original entrepreneur. For instance, Gorman and Sahlman (1989) argue that venture capitalists frequently replace the original founders as CEO. Hellmann and Puri (1999) find that venture-backed firms experience 
such replacement twice as much as non-venture-backed firms. ${ }^{4}$

Summary of the Model: Built on the two assumptions described above, I study the funding problem of an entrepreneur who privately knows the quality of her project at the outset. The entrepreneur may disclose this idea to either the bank or $\mathrm{VC}$ so as to demonstrate her creditworthiness. If the entrepreneur discloses to the bank, the bank observes a signal that is imperfectly related to the quality of the project. Thus, information asymmetry persists to some degree between the entrepreneur and the bank, and the bank attempts to screen out bad quality projects using both collateral and interest requirements. If the entrepreneur discloses to $\mathrm{VC}, \mathrm{VC}$ becomes as well informed of the project quality as the entrepreneur.

The optimal financing choice depends on the entrepreneur's collateral, how tightly intellectual property rights to the project are protected and the profitability and the size of the project,. First, if the entrepreneur has little collateral to pledge to the bank, the entrepreneur raises funds from VC. This is because the asymmetric information problem is acute and the bank uses a too high rate of interest as a screening device. As a consequence, the entrepreneur goes to the $\mathrm{VC}$ that does not require collateral in order to avoid this potential high-rate of interest charged by the bank. Second, if the intellectual property rights to the project is tightly protected, the entrepreneur raises funds from the VC. The reason is that the VC's threat to duplicate the project is weak. As a consequence, the entrepreneur enjoys only the bright side of expertise: better screening ability. Third, if the project has a high rate of return and/or is large, the entrepreneur tends to finance from VC. The reasons are as follows: if VC were to expropriate such a project, the entrepreneur would be likely to sue VC

\footnotetext{
${ }^{4}$ Feeney et. al. (1998) present a related finding from an extensive survey of Canadian business owners conducted from October 1997 throught May 1998. They find that only $6 \%$ of the sample relies on venture capital which makes a sharp contrast to $54 \%$ on bank. Furthermore, they ask the business owners who avoid issuing outside-equity why they do so. They find that $38.9 \%$ of the sample fear a danger of losing the control of their companies by issuing outside equity.
} 
because the compensation from $\mathrm{VC}$ would be large. Thus, the entrepreneur can effectively commit to penalize VC in case VC may expropriate the project. This entrepreneur's threat to penalize VC reduces the VC's threat to expropriate the project. The entrepreneur's payoff financing from VC therefore becomes larger and financing from $\mathrm{VC}$ becomes more attractive to the entrepreneur.

When interpreting the ratio of the project size to the entrepreneur's collateral as growth rate of the firm, the model predicts that the entrepreneur tends to raise funds from $\mathrm{VC}$ when the growth rate of the project is large. This is because, both low collateral and big size of the project drive the entrepreneur to finance from $\mathrm{VC}$.

These predictions of the model fit well into the empirical observations on the projects that VC typically finance. First, banks are known to make loans based on collateral while VCs supply portfolio firms with funds in exchange of equity. Second, VC-backed firms typically grow faster than non VC-backed firms. Hellmann and Puri (2000) find that VC-backed firms hire more employees than non- $\mathrm{VC}$ backed firms controlling the firm age.

The model also suggests that the recent growth of the venture capital industry may be driven by the broader and extended patent policy in the US. The US patent office recently extended the definition of "novelty" and started to grant patents to business ideas or models. As a consequence, in 1999, there is a heated debate on patenting business ideas. For instance, "an editorial discusses the recent spate of Internet patent lawsuits, asking if we can really take seriously Amazon.com's claim that its 1-Click express checkout capability is a unique and patent-worthy invention that Barnesandnoble.com should not be allowed to imitate." (Computerworld, Dec. 1999) Nonetheless, "in two landmark cases, the US Court of Appeal for the Federal Circuit has recently made clear that methods of doing business are not beyond the purview of patent protection." (Electronic Business, Jan. 2000). Interpreting this pro-patent policy as tightening intellectual property protection, the model explains why venture 
capital has grown so fast lately.

Stronger protection of property rights may account not only for the recent growth of VC but also for the early 80s growth. In 1982, the Court of Appeals of the Federal Circuit, was established by US Congress. The new court has been widely regarded as being tougher in enforcing intellectual property rights as before. (Merges, 1992). To be consistent with the model, Figures 1 and 2 show that venture capital investment jumped from 1982 to 1983.

Literature: There is a long list of literature that is related to this paper. First, similar to my model, some authors attempt to develop a model of financial intermediaries in the presence of information problems. For instance, Chan (1983) compares the economy with screening agents (VC) and the one without, and shows that introducing such agents enhances welfare. Similar to my model, the fundamental market friction of his model is information asymmetry between entrepreneur and investors. Holmstrom and Tirole (1997) and Dessi (1998) develop a model of financial intermediaries that can monitor how much an entrepreneur makes efforts. These two papers share with this present paper the prediction that entrepreneurs finance from VC if they are running short of collateral.

Second, this paper stands along the line of research on financing in the absence of intellectual property rights. For instance, Bhattacharya and Ritter (1983) and Yosha (1995) study the optimal degree of disclosure based on the trade-off between better screening and threat of expropriation as in this paper. Anton and Yao (1994) study the mechanism to circumvent the underinvestment problem associated with misappropriation of research efforts. Nonetheless, these three papers all consider only one type of financier. As a consequence, they do not ask why heterogeneous financiers, bank and VC exist. One exception is Anand and Galetovic (1998) that compares financing by VC and by corporation. They show that when property rights are strong, the entrepreneur finances from the $\mathrm{VC}$ at first and then from the corporation. And 
when property rights are weak, either the corporation or the $\mathrm{VC}$ finances the entire life of the entrepreneur.

Finally, I want to point out what this paper does not explain and which literature explores the points omitted in this paper. To focus on the choice between bank and VC, my model of VC financing is parsimonious. The optimal contract determines the division of the surplus between the entrepreneur and $\mathrm{VC}$ alone and there is no expropriation by $\mathrm{VC}$ in equilibrium. Venture capital contracts are much more complicated in reality, however. (See Gompers, 1995 and 1997, and Kaplan and Stromberg, 2000) The allocation of surplus depends on many types of circumstances and venture capital often replaces the founders of the portfolio firms. The failure in explaining those features by my model is originated from not taking account for many important considerations in venture capital financing such as learning, asymmetric information and moral hazard between VC and entrepreneur, and private benefits of entrepreneur. These aspects have been widely studied, however. Incorporating learning features into the model, Admati and Pfleiderer (1994) and Bergemann and Hege (1998) explain why venture capital typically stages financing. Cornelli and Yosha (1997) explain the frequent use of convertible debts in venture capital financing when the entrepreneur knows the information that VC does not know. Hellmann (1998) studies the ownership transfer of venture-backed firms when the VC searches for a manager more skilled than the founder of the firm. Casamatta (2000), Repullo and Suarez (1999), and Schmidt (2000) also justify the use of convertible debts by $\mathrm{VC}$ when $\mathrm{VC}$ makes an unobservable effort to enhance the value of the portfolio firm. Berglof (1997) studies the optimal allocation of control rights between entrepreneur and $\mathrm{VC}$ when the entrepreneur enjoys private benefits of control. Under a similar assumption, Kilirenko (2001) studies how much control the entrepreneur should give up in order to signal the value of the firm. For a more detailed survey, see Lerner and Gompers (1999).

The rest of the paper is organized as follows. Section 2 sets up the model. 
Section 3 derives and characterizes equilibrium. Section 4 discusses the assumptions and the results of the model. Section 5 concludes.

\section{The Model}

This section presents the economy in that an entrepreneur chooses either bank or $\mathrm{VC}$ as the sole external financier. All agents are risk neutral and the risk free interest rate is normalized to zero. There are three players: "E" (entrepreneur), "VC" (venture capitalist), and "B" (bank). Although there are only one VC and $\mathrm{B}$ in the model, both $\mathrm{VC}$ and $\mathrm{B}$ belong to competitive venture capital and banking industries, respectively. This assumption will be clarified later on.

At the outset, E discovers a blueprint of a project that requires $F$ units of capital as the outlay. $\mathrm{E}$ is initially endowed with collateral the value of which is $W$ units of capital. I assume $W<F$ such that E cannot issue a fully collateralized debt to raise $F$. If the project is undertaken, it returns $R F$ with probability $p$ and zero with probability $1-p$. At the outset, this success probability, $p$ is uncertain and can be either $p_{h}$ or $p_{l}$ with equal probability. I assume that:

$$
p_{h} R>1>p_{l} R
$$

That is, undertaking the project is profitable if $p=p_{h}$, and not profitable otherwise. Note that the value of the project, $p R F$, does not depend on who, either B or VC, finances the project. That is, I assume away advisory or valueenhancing roles of $\mathrm{VC}$ from the model. For simplified notation, let $\Phi$ be equal to $p_{h}(R-1) F$, which is the net present value of the profitable project.

\subsection{Disclosure, Assessment, and Expropriation}

Assessing the Project: Initially, E becomes privately informed of the true value of $p$. Nonetheless, E can communicate with either B or VC, or both about the true $p$ by disclosing the contents of the project. When $\mathrm{E}$ discloses her project to $\mathrm{VC}, \mathrm{VC}$ identifies the realization of $p$ without error. On the other hand, when 
E discloses to B, B observes a signal, $s$, which is imperfectly correlated with the realization of $p$. This signal, $s$ is either $\bar{s}$ or $\underline{s}$. The conditional probability of the signal is $\operatorname{prob}\left(\bar{s} \mid p_{h}\right)=\operatorname{prob}\left(\underline{s} \mid p_{l}\right)=\alpha$, and $\left(\bar{s} \mid p_{l}\right)=\operatorname{prob}\left(\underline{s} \mid p_{h}\right)=1-\alpha$, where $\alpha \geq$.5. The index $\alpha$ measures the knowledge gap between B and VC. This gap is the largest if $\alpha=.5$, in which case disclosing the project to B conveys no information about the quality of the project. On the other hand, if $\alpha=1, \mathrm{~B}$ has the same ability to identify the quality as VC does. In knowledge-based industries, $\alpha$ is presumably low because understanding the details of the project requires advanced technological knowledge

Below, I refer a project that has the successful probability, $p_{h}\left(p_{l}\right)$, as the profitable (unprofitable) project, and $\mathrm{E}$ that holds the profitable (unprofitable) project, as profitable (unprofitable) E.

Imperfect Protection of Intellectual Property Rights: Once E discloses the project to $\mathrm{VC}, \mathrm{VC}$ can expropriate the E's project, that is, undertake it by his own. In practice, $\mathrm{VC}$ may expropriate it by passing the project content to a firm in that $\mathrm{VC}$ has been already investing and by having the firm to undertake the project. If this expropriation happens, VC may have to pay a certain amount of compensation to E. The expected amount of this compensation may depend on both the profitability of the project, $\Phi$ and $q$ which measures how tightly intellectual property rights are protected. To be concrete, let $L=L(\Phi, q)$ be the expected compensation that VC has to pay to $\mathrm{E}$ if $\mathrm{VC}$ expropriates the E's project. I assume that $L$ is non-negative and non-decreasing in both entries. The reason for assuming that $L$ is non-decreasing in $\Phi$ is that the higher the value of the project, the more the damage that $\mathrm{E}$ incurs from the expropriation by $\mathrm{VC}$ is. And $\mathrm{E}$ can possibly demand a higher amount of compensation from VC. The index, $q$ is presumably large if the legal system approves intellectual property rights to broad scope, or the system is more efficient in seizing incidents of expropriation. 


\subsection{Contracting Structure}

No matter which B or VC finances E, the financial contract specifies the payments contingent on the return to the project. Let $\pi_{H}$ and $\pi_{L}$ be the payments to $\mathrm{E}$ if the project is successful and fails, respectively.

\subsection{Sequence of Events}

There are three dates:

Date 0 (B Offers a Menu of Contracts): Knowing the realization of $p, \mathrm{E}$ discloses the project to $\mathrm{B}$, and $\mathrm{B}$ observes the signal $s$. Because $\mathrm{B}$ is not still sure about the true quality of $\mathrm{E}, \mathrm{B}$ tries to distinguish the quality by offering a menu of contracts to E. This offer is made as the same manner as in Bester (1985). He applies the competitive insurance market model of Rothschild and Stiglitz (1976) to banking under asymmetric information. In the Bester's model, each bank seeks to maximize its profit under perfect competition and in equilibrium each bank offers a menu of contracts to entrepreneurs for the purpose of sorting out entrepreneurs' projects according to their profitability. Some contracts in the menu are profitable to the bank and others are not. Because of the competitive market assumption, in equilibrium each bank designs its menu of contracts so as to maximize the payoff of the most profitable entrepreneur under the constraints such that the bank's profit is zero on average and each entrepreneur is motivated to reveal her true type. In this Bester's model, there is no credit rationing in equilibrium and all projects with a positive net present value will be financed. ${ }^{5}$ The same sorting mechanism is adopted in this paper. ${ }^{6}$

To be concrete, $\mathrm{B}$ offers $\mathrm{E}$ a risky contract which is meant to attract the profitable project, $p=p_{h}$, and a safe contract which is meant to attract the unprofitable project, $p=p_{l}$. Under the risky contract, B lends $F$ to E. If the

\footnotetext{
${ }^{5}$ In Bester and this paper, analogous to the result of Rothschild and Stiglitz, separating equilibria alone may exist: by choosing a contract, B reveals her type. Unlike Rothschild and Stiglitz, an equilibrium always exists because $\mathrm{E}$ is risk neutral.

${ }^{6}$ One difference between Bester and this paper is that all projects have positive net present values in Bester on the one hand, some projects may not have a positive net present value in this paper on the other.
} 


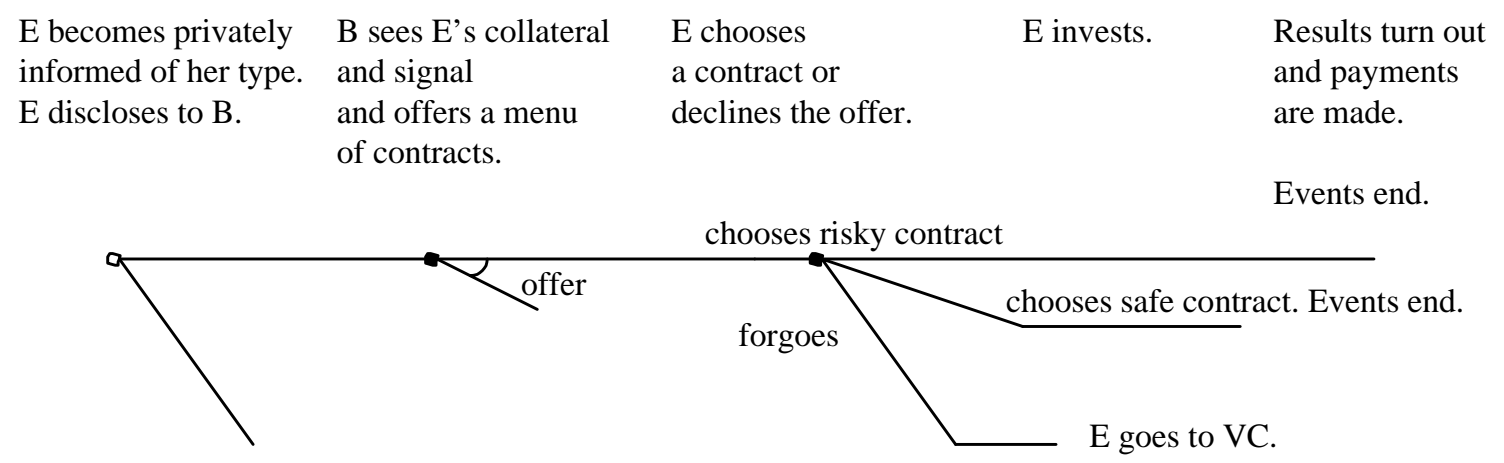

Figure 3:

project is successful, E gets $\pi_{H}+W$ and $\mathrm{B}$ gets $R F-\pi_{H}$. If $\mathrm{E}$ fails in the project, she gets $\pi_{L}^{B}+W$ and B gets $-\pi_{L}^{B}$. Under the safe contract, B transfers $T$ to E. Summing up, a risky/safe contract pair is expressed by a triplet $\left\{\pi_{H}, \pi_{L}^{B}, T\right\}$.

Date 1 (E's Choice of a Contract): E has three options: to dismiss B and go to $\mathrm{VC}$, to choose the safe contract, or to choose the risky contract. If $\mathrm{E}$ chooses the safe contract, the transfer will be made and events will end; If $\mathrm{E}$ chooses the risky contract, she invests $F$ in the project. The return to the project is then realized and payments are made. The events that occur in dates 0 and 1 are summarized in Figure 2.

Date 2 (Contracting with $V C$ ): If E dismisses the B's offers, E discloses her idea to VC. If she has the unprofitable project, events end. ${ }^{7}$ If she has the profitable project, E makes a take it or leave it offer of a contract to $\mathrm{VC}{ }^{8}$ Similar to the contract with B, E's offer specifies the payment to E depending on the return to the project. E receives $\pi_{H}$ if the return is $R F$ and $\pi_{L}^{V C}$ if the return is zero. VC then decides whether to accept the contract. If he accepts

\footnotetext{
${ }^{7}$ Here, I implicitly assume an equilibrium story in that VC should not finance the unprofitable E.

${ }^{8}$ At a first glance, this negotiation process may appear to be asymmetric to the one with a bank who offers a menu of contracts. These specifications of negotiation processes, however, will turn out to be consistent and symmetric in the sense that the innovator has all the bargaining power for both processes. This is because I will assume that a bank's offer must be competitive.
} 


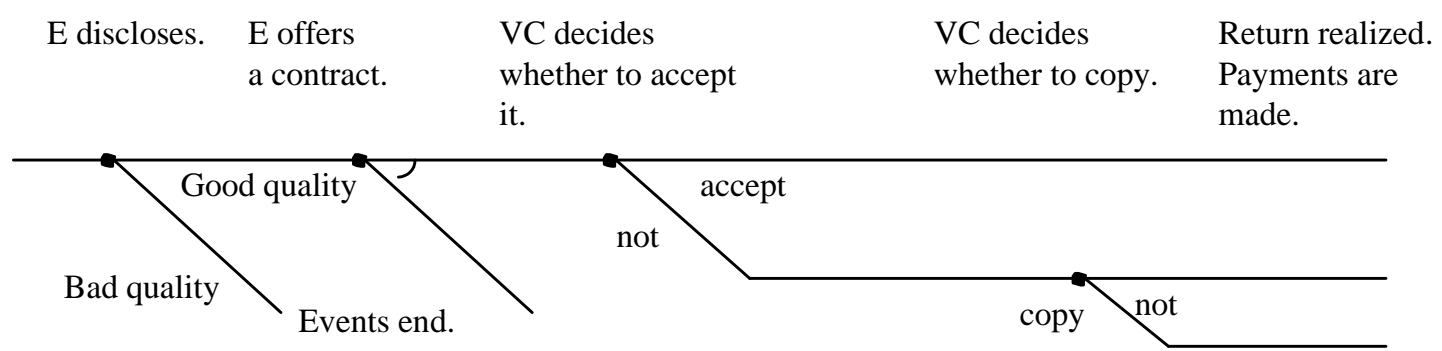

Figure 4:

it, he supplies $F$ to $\mathrm{E}$ and $\mathrm{E}$ undertakes the project. If $\mathrm{VC}$ declines, he decides whether to expropriate the project. If $\mathrm{VC}$ expropriates, the distribution of the project return is the same as if $\mathrm{E}$ undertakes the project and $\mathrm{VC}$ receives the full amount of return to the project. Lastly, If $\mathrm{VC}$ expropriates, $\mathrm{E}$ decides whether to sue $\mathrm{VC}$ or not. The events that occur in this date is summed up in Figure 3.

Note that this specification of the sequence does not allow VC to duplicate the project after he decided to accept E's offer and to finance the project. When the project is significantly profitable or $\mathrm{VC}$ can substantially differentiate its product from E's one, VC may still have an incentive to duplicate the project and enter the product market competition with E. Nonetheless, to maintain the model simple as possible, I exclude this possibility and assume that the project is not profitable enough if two parties undertake the project. ${ }^{9}$

\subsection{Equilibrium}

This section solves and characterizes the equilibrium strategies of E, B, and VC. The solution concept adopted is perfect Bayesian equilibrium. Since an equilibrium must satisfy backward induction, the following exposition starts from Date 2.

There are to remarks before proceeding to solve the equilibrium. First, note

\footnotetext{
${ }^{9}$ Ueda (1997) discusses the case in which VC and E may enter the product market competition. The results would not change however.
} 
that hereafter "E's expected payoff" means E's net payoff that is equal to an incremental payoff due to a contract with either B or VC. E's expected payoff plus $W$ is E's expected gross (or total) payoff. Second, note that any characters with upper bar is associated with $\mathrm{E}$ with the good signal and any characters with lower bar is associated with $\mathrm{E}$ with the bad signal.

\subsubsection{Equilibrium at Date 2}

If $\mathrm{VC}$ were to decline the E's offer of a contract, the VC's optimal strategy is to expropriate the E's project if $L(\Phi, q) \leq \Phi$ and is not to expropriate if $L(\Phi, q)>$ $\Phi$. To focus on an interesting case in that the VC's threat to expropriate is relevant, I assume that $L(\Phi, q) \leq \Phi$ hereafter. Under this assumption, if VC were to decline the E's offer, the VC's expected return is equal to the expected return to the project minus the expected penalty:

$$
X \equiv \Phi-L(\Phi, q)
$$

where I call $X$ the expropriation gain. It is non-decreasing in $q$, that is, VC has less incentives to expropriate the project if intellectual property rights are more securely protected.

The expropriation gain $X$ gives the threat point of $\mathrm{VC}$ when $\mathrm{E}$ and $\mathrm{VC}$ negotiate on contracts. To persuade VC to accept the contract, it must guarantee VC with payoff at least as much as $X$. Thus, E's offer should maximize her expected payoff,

$$
p_{h} \pi_{H}^{V C}+\left(1-p_{h}\right) \pi_{L}^{V C}
$$

subject to the VC's participation constraint

$$
p_{h}\left(R F-\pi_{H}^{V C}\right)-\left(1-p_{h}\right) \pi_{L}^{V C}-F \geq X
$$

Lemma 1 In equilibrium at date 2, the E's expected payoff is equal to

$$
U^{V C} \equiv \Phi-X=L(\Phi, q)
$$


Proof:

The proof is divided into two steps. The first step involves showing that $L(\Phi, q)$ is the upper bound for the expected payoff of profitable E. The second step is to show that there exists a contract $\left\{\pi_{H}, \pi_{L}^{V C}\right\}$ which attains this upper bound and satisfies all the constraints. Rewriting the participation constraint (2), I obtain

$$
p_{h} \pi_{H}^{V C}+\left(1-p_{h}\right) \pi_{L}^{V C} \leq \Phi-X \equiv L(\Phi, q)
$$

Set $\pi_{H}$ and $\pi_{L}^{V C}$ such that the above equation is an equality. The no-expropriation constraint can be satisfied by appropriating choosing $\pi_{H}$ and $\pi_{L}^{V C}$. Q.E.D.

The entrepreneur's payoff is strictly less than the total rent $\Phi$ since the VC captures a part of the rent to the project by threatening $\mathrm{E}$ with a possibility of the expropriation. This positive rent $X$ is the cost to $E$ for revealing valuable information to VC who could possibly steals the project.

The proof implies that an E's offer is optimal if and only if it satisfies

$$
p_{h} \pi_{H}^{V C}+\left(1-p_{h}\right) \pi_{L}^{V C}=L(\Phi, q) .
$$

There are two unknowns $\pi_{H}$, and $\pi_{L}^{V C}$, and just one equation. Thus unknowns are not uniquely determined.

\subsubsection{Equilibrium at Date 1}

As described in the previous section, profitable E can get $L(\Phi, q)$ by declining the offer from B and financing from VC. If unprofitable E does this, she gets zero. Thus in equilibrium at date 1, profitable E should accept a contract offered by $\mathrm{B}$ only if one of the contracts in the menu gives $\mathrm{E}$ at least as much as $L(\Phi, q)$. Unprofitable E should accept one of the contracts only if it offers a non-negative expected payoff to her. 


\subsubsection{Equilibrium at Date 0}

Given the E's optimal strategy described above, B offers a menu of contracts $\left\{\pi_{H}, \pi_{L}^{B}, T\right\}$. The optimal offer strategy of B will be solved in two steps. First, I derive the optimal offer if there were no $\mathrm{VC}$ and if E's reservation payoff when declining the B's offer would be equal to zero. This case is the same as Bester (1985). He shows that a bank in a competitive banking industry finances any positive net present value projects in equilibrium and the entrepreneur's payoff is strictly greater than zero if she has such a positive net present value project. This result implies that without an opportunity to ask VC for funds, the participation constraint that profitable $\mathrm{E}$ would accept an offer from B were not binding. Hence, to simplify the exposition below, I omit the participation constraint of profitable E.

Let $U_{B}$ be this benchmark payoff in absence of $\mathrm{VC}$. Note that $U_{B}$ is derived under the belief that profitable E will accept B's offer and, on average, this prospect compensates the loss from transferring $T$ to unprofitable E. After deriving $U_{B}$, I move to the second step and introduce the possibility that profitable E can turn down the B's offer and goes to VC. In this case, the reservation payoff of unprofitable $\mathrm{E}$ remains zero while the one of profitable $\mathrm{E}$ becomes $L(\Phi, q)$. If $U_{B} \geq L(\Phi, q)$, the belief set up in the first step is consistent and the offer strategy of B derived in the first step is indeed the equilibrium strategy. On the other hand, if $U_{B}<L(\Phi, q)$, the belief set up in the first step is inconsistent and the offer strategy of B derived in the first step is not an equilibrium strategy. As a consequence, if $U_{B}<L(\Phi, q)$, the optimal offer strategy of $\mathrm{B}$ is to make a trivial offer such that neither type of $\mathrm{E}$ accepts, for instance $\{-\varepsilon,-\varepsilon,-\varepsilon\}, \varepsilon<W$. By making such a trivial offer, B's expected profit is zero and this is equal to the reservation payoff of B. Note that B should never offer a menu of contracts such that unprofitable $\mathrm{E}$ is expected to accept while profitable $\mathrm{E}$ is not. This is because $T$ must be positive for unprofitable $\mathrm{E}$ to accept. As far as E may be unprofitable with a positive probability, making 
such an offer gives B a negative profit. Thus, B becomes strictly better off by making a trivial offer.

Now I start to derive the benchmark payoff $U_{B}$. Since B belongs to a competitive banking sector, B consequently maximizes profitable E's expected payoff much like in Bester. Unlike in Bester, B's expected profit for each offer will be zero conditional on E's signal. In particular, having observed E's signal $s$, B revises its prior belief about the E's quality. The posterior probability with which $p=p$ is

$$
\operatorname{prob}\left(p=p_{h} \mid s=\bar{s}\right)=\frac{.5 \alpha}{.5 \alpha+.5(1-\alpha)}=\alpha,
$$

$\operatorname{prob}\left(p=p_{l} \mid s=\underline{s}\right)=\alpha, \operatorname{prob}\left(p=p_{l} \mid s=\bar{s}\right)=\operatorname{prob}\left(p=p_{h} \mid s=b\right)=1-\alpha$. Based on this posterior belief, $\mathrm{B}$ offers a menu of contracts.

1. When $\bar{s}$ is observed.: First, I examine the optimal offer when B observes the good signal, $\bar{s}$. B chooses a menu of contracts to offer so as to maximize the expected payoff for profitable E,

$$
p_{h} \pi_{H}^{B}+\left(1-p_{h}\right) \pi_{L}^{B}
$$

subject to the B's zero profit constraint,

$$
\alpha\left[\Phi-\left\{p_{h} \pi_{H}^{B}+\left(1-p_{h}\right) \pi_{L}^{B}\right\}\right]-(1-\alpha) T=0,
$$

the incentive compatibility condition, ${ }^{10}$

$$
p_{l} \pi_{H}^{B}+\left(1-p_{l}\right) \pi_{L}^{B} \leq T
$$

the limited liability condition under which a negative payoff is not possible,

$$
\pi_{L}^{B} \geq-W
$$

and the unprofitable E's participation constraint,

$$
T \geq 0
$$

\footnotetext{
${ }^{10}$ In equilibrium, the incentive compatibility condition under which an good quality entrepreneur will not choose the contract intended for a bad quality entrepreneur is not binding.
} 
Lemma 2 The expected payoff for profitable $E$ if she has the good signal is

$$
\overline{U^{B}} \equiv \min \left[\Phi, \frac{\alpha p_{h} \Phi}{\bar{p}}+\left(\frac{p_{h}}{\bar{p}}-1\right) W\right]
$$

the expected payoff for unprofitable if she has the good signal is

$$
\overline{T^{B}}=\max \left[0, \frac{\alpha}{\bar{p}}\left\{p_{l} \Phi-\left(p_{h}-p_{l}\right) W\right\}\right],
$$

where $\bar{p}=\alpha p_{h}+(1-\alpha) p_{l}$.

Proof:

The proof will proceed in a similar way to the proof of Lemma 1. Using the B's zero profit condition (5), the incentive compatibility condition (6) can be rewritten as follows:

$$
\pi_{H}^{B} \leq \frac{\alpha \Phi-\left\{(1-\alpha)\left(1-p_{l}\right)+\alpha\left(1-p_{h}\right)\right\} \pi_{L}^{B}}{\bar{p}} .
$$

Then, from (7), we have

$$
\begin{aligned}
p_{h} \pi_{H}^{B}+\left(1-p_{h}\right) \pi_{L}^{B} & \leq p_{h} \frac{\alpha \Phi-\left\{(1-\alpha)\left(1-p_{l}\right)+\alpha\left(1-p_{h}\right)\right\} \pi_{L}^{B}}{\bar{p}}+\left(1-p_{h}\right) \pi_{L}^{B} \\
& \leq \frac{\alpha p_{h} \Phi}{\bar{p}}+\left(\frac{p_{h}}{\bar{p}}-1\right) W
\end{aligned}
$$

This upper bound for the expected payoff for profitable $\mathrm{E}$ if she has the good signal can be achieved by setting $\pi_{L}^{B}=-W$, and

$$
\pi_{H}^{B}=\frac{\alpha \Phi+W}{\bar{p}} .
$$

These values can be shown to satisfy all the constraints.

Furthermore, sticking $\pi_{H}=-W$ and (9) into (5) and (6), and solving with respect to $T$, we obtain $\overline{T^{B}}$.

Q.E.D.

2. When the bad signal is observed: The B's problem when the bad signal is observed is identical to the one when the good signal is observed EXCEPT that the B's participation constraint (5) is replaced with

$$
(1-\alpha)\left[\Phi-\left\{p_{h} \pi_{H}^{B}+\left(1-p_{h}\right) \pi_{L}^{B}\right\}\right]-\alpha T \geq 0 .
$$


Lemma 3 The expected payoff for profitable $E$ if she has the bad signal is

$$
\underline{U^{B}}=\min \left[\Phi, \frac{(1-\alpha) p_{h} \Phi}{\underline{p}}+\left(\frac{p_{h}}{\underline{p}}-1\right) W\right] ;
$$

the expected payoff for unprofitable $E$ if she has the bad signal is

$$
\underline{T^{B}}=\max \left[0, \frac{1-\alpha}{\underline{p}}\left\{p_{l} \Phi-\left(p_{h}-p_{l}\right) W\right\}\right],
$$

where $\underline{p}=(1-\alpha) p_{h}+\alpha p_{l}$.

Proof: Similar to the proof of lemma 2.

Now I move to the second step and introduce VC. B should offer the menu of contract that solves the above problem if and only if B believes that profitable E will accept as argued before. Otherwise, B knows that only unprofitable E would accept an offer. Thus B's optimal strategy is to offer the menu of contracts if and only if $U^{B}$ is at least as much as $L$. Otherwise, B should make a trivial offer.

Having derived $U_{B}$, we are now ready to determine under what conditions E finances from B and from VC. The following proposition follows lemmas 2 and 3 .

Proposition 1 If $E$ has the profitable project and the good signal, then she finances from $B(V C)$ if and only if:

$$
\overline{U_{B}} \equiv \min \left[\Phi, \frac{\alpha p_{h} \Phi}{\bar{p}}+\left(\frac{p_{h}}{\bar{p}}-1\right) W\right] \geq L(\Phi, q)
$$

If $E$ has the profitable project and the bad signal, then she finances from $B(V C)$ if and only if:

$$
\underline{U_{B}} \equiv \min \left[\Phi, \frac{(1-\alpha) p_{h} \Phi}{\underline{p}}+\left(\frac{p_{h}}{\underline{p}}-1\right) W\right] \geq L(\Phi, q) .
$$

How about the payoff of unprofitable E? To be concrete, let $\bar{I}(W, \alpha, \Phi, q)$ be an index function such that given $p_{h}$ and $p_{l}, \bar{I}=0$ if the equation (10) is not satisfied and $\bar{I}=1$ if the equation (10) is satisfied, and let $\underline{I}(W, \alpha, \Phi, q)$ be 
another index function such that $\underline{I}=0$ if the equation (11) is not satisfied and $\underline{I}=1$ if the equation (11) is satisfied. In other words, the index functions, $\bar{I}$ and I map the E's characteristics into her choice of financing source. If profitable E has the good (bad) signal and her characteristics gives $\bar{I}(\underline{I})=0$, she finances from VC. If profitable $\mathrm{E}$ has the good (bad) signal and her characteristics give $\bar{I}(\underline{I})=1$, she finances from B. Then, the payoff of unprofitable $\mathrm{E}$ is zero if she has the good (bad) signal and her characteristics give $\bar{I}(\underline{I})=0$. This is because B rationally believes that profitable $\mathrm{E}$ whose characteristics give $\bar{I}(\underline{I})=0$ would not accept the benchmark offer and that $\mathrm{B}$ cannot make such $\mathrm{E}$ better off compared to financing from VC. On the other hand, the payoff of unprofitable $\mathrm{E}$ is $\bar{T}(\underline{T})$ if she has the good (bad) signal and her characteristics give $\bar{I}(\underline{I})=1$. This is because $\mathrm{B}$ rationally believes that profitable $\mathrm{E}$ whose characteristics give $\bar{I}(\underline{I})=1$ accept the benchmark offer and that the expected gain from lending to profitable E can compensate the expected loss from a non-negative transfer to unprofitable E.

\section{Empirical Implications}

In this section, I characterize the equilibrium source of financing and discuss the empirical implications of the model.

\subsection{Low collateral entrepreneur goes to VC}

It is commonly observed that a bank requires collateral when making loans while a venture capitalist does not. This observation is confirmed in this model.

Corollary 1 Both $\bar{I}$ and $\underline{I}$ are non-decreasing in $W$. That is, profitable $E$ finances from $V C$ if her collateral is low, and from $B$ if her collateral is high.

Proof: The proposition follows that the left hand sides of both equations (10) and (11) are non-decreasing in $W$.

Figure 5 visualizes this corollary by plotting $\overline{U^{B}}, \underline{U^{B}}$, and $U^{V C}(=L) . U^{V C}$ is constant and does not depend on $W$ while both $\overline{U^{B}}$ and $\underline{U^{B}}$ are increasing 


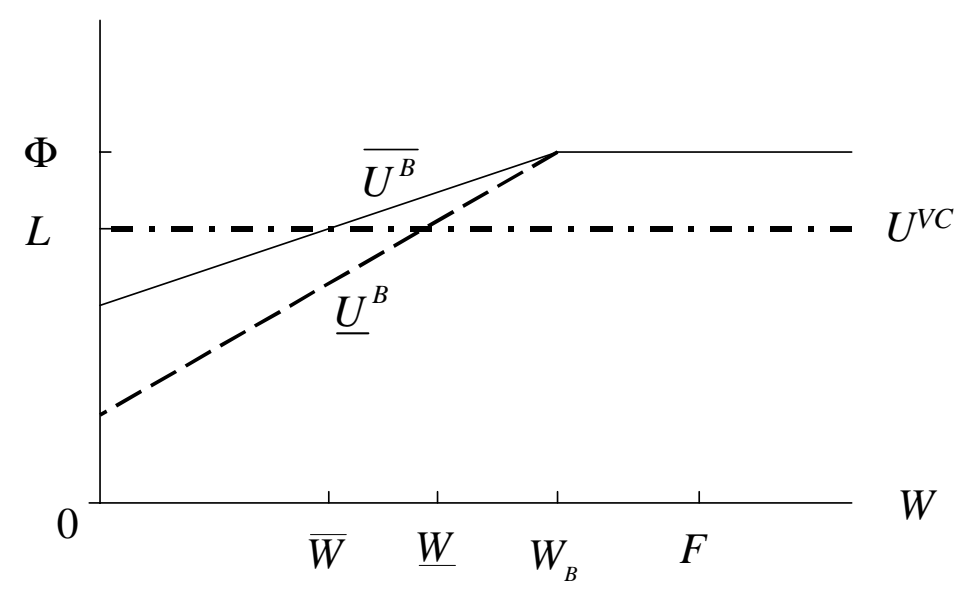

Figure 5:

in $W$. As a consequence, $\mathrm{VC}$ is more attractive source of financing relative to B when E's collateral is low. This is because $\mathrm{E}$ and VC contract without asymmetric information while $\mathrm{E}$ and $\mathrm{VC}$ do under asymmetric information. As the collateral increases, B can recover a higher amount of loans even the project fails and can penalize unprofitable E more harshly if she would have chosen the contract meant for profitable E. Due to this tougher punishment, unprofitable $\mathrm{E}$ is willing to accept a lower amount of the transfer, $T$, and $\mathrm{B}$ can decrease the expected loss in case that $\mathrm{E}$ turns out the unprofitable type and can increase $\pi_{H}$ without violating the zero profit condition. As a consequence, profitable $\mathrm{E}$ can obtain a better term of a contract from B. By interpreting $\left(R F-\pi_{H}\right) / F$ as the interest rate that $\mathrm{B}$ charges to profitable $\mathrm{E}$, increasing $\pi_{H}$ means reduction of the interest rate. Similar to the results of Bester (1984), and De Meza and Webb (1987), the model implies that if the entrepreneur's collateral is high, the interest rate becomes low. In an extreme case, if her collateral is no less than

$$
W_{B} \equiv \frac{p_{l} / p_{h}}{1-p_{l} / p_{h}} \Phi
$$

profitable E can capture the entire rent of the project as she would if there would be no asymmetric information. 
Furthermore, $\overline{U^{B}}>\underline{U^{B}}$ if $W<W_{B}$. When her signal is good, profitable $\mathrm{E}$ can enjoy a lower rate of interest rate than one when her signal is bad. This is because when E's signal is good, B believes that E is unlikely to turn out to be of unprofitable type. Thus, the expected loss from transferring $T$ is low and B can lower the interest rate relative to the case that the signal is bad. As a consequence, the threshold amount of collateral at which E switches between $\mathrm{B}$ and $\mathrm{VC}$ is lower if $\mathrm{E}$ has the good signal than if $\mathrm{E}$ has the bad signal. (In Figure 5, the threshold for $\mathrm{E}$ with the good signal is denoted by $\bar{W}$ and the one for $\mathrm{E}$ with the bad signal is denoted by $\underline{W}$, respectively.)

\subsection{Entrepreneur with secure IPR goes to VC.}

In this model, the financing decision of the entrepreneur also depends on how tightly intellectual property rights to the project are protected.

Corollary 2 Both $\bar{I}$ and $\underline{I}$ are non-increasing in $q$. That is, profitable $E$ finances from VC if the intellectual property rights to her project is securely protected, and from $B$ if not.

Proof: The proposition follows that the right hand sides of both equations (10) and (11) are non-decreasing in $q$.

When E holds secure property rights to her project, VC's threat to expropriate the project becomes weak. In the extreme case in that $L(\Phi, q)$ is as much as $\Phi, \mathrm{VC}$ 's threat is not effective at all. In this case, profitable E can enjoy only the bright side of VC that has a better identification skill than B. Thus, $\mathrm{E}$ discloses the project to and finances from VC.

This proposition suggests that the choice of financing source depends on the legal environments that determines the degree of intellectual property rights protection. For instance, the US patent office is known to have become more generous in approving patents lately. They advanced in approving software patents and lately business ideas. Thus, the recent dramatic growth of the US 
venture capital industry may be driven by this pro patent policy and therefore weaker threat of the expropriation by $\mathrm{VC}$.

\subsection{Entrepreneur with a large project goes to VC}

It is common notion that venture capital backed firms grow fast. Hellmann and Puri (2000) quantitatively confirm this notion by studying firms located in Sillicon Valley. To be concrete, they find that venture-backed firms hire more employees controlling for the firm age and industry. Thus, this finding implies that venture-backed firms have large projects relative to non-venture baked counterparts. The authors interpret this result that venture capitalists are able to grow their portfolio firms faster. Nonetheless, there is an alternative interpretation: firms with a large project and a high-growth prospect may choose to raise funds from venture capital. In what circumstances, this alternative interpretation arises from the present model? Let us take $F$ as the proxy of firm size.

The model as it is does not unambiguously imply that $\mathrm{E}$ finances from $\mathrm{VC}$ if $F$ is larger. Note that $\bar{I}$ and $\underline{I}$ are not always non-increasing in $F$ because both hand sides of the equations (10) and (11) are non-decreasing in $F$. Roughly speaking, E can get more from both $\mathrm{B}$ and $\mathrm{VC}$ when $F$ is larger. Thus, the effect of $F$ on the financing choice crucially depends on the shape of the function, $L(\Phi, q)$, in which $\Phi$ depends on $F$. One reasonable assumption to specify the form of, $L(\Phi, q)$ is motivated by the compensation rule under that if E sues $\mathrm{VC}$ and if the judge ascertains the VC's fault, VC has to compensate E paying the profit to the project. By interpreting $q$ as the probability that the judge ascertains the VC's fault, the expected penalty that VC has to pay, $L(\Phi, q)$, is specified as $q \Phi$. Since $\Phi \equiv\left(p_{h} R-1\right) F$, we can rewrite as $L=q\left(p_{h} R-1\right) F$. I continue to assume that $L<\Phi$, which is equivalent to $q<1$.

Noting that now $U^{V C}=q\left(p_{h} R-1\right) F$, the model implies the following:

Corollary 3 Both $\bar{I}$ and $\underline{I}$ are non-increasing in $F$. That is, $E$ finances from 
$V C$ if the E's project is large and from $B$ if it is small.

Proof: Take $\overline{U^{B}}, \underline{U^{B}}$, and $U^{V C}$ as functions of $F$. The proof consists of the two steps: in the first step, we see that both $\overline{U^{B}}$ and $\underline{U^{B}}$ are strictly greater than $U^{V C}$ if $F$ is small enough and in the second step, we see that $U^{V C}$ crosses each $\overline{U^{B}}$ and $\underline{U^{B}}$ at most once.

$$
F^{*}=\frac{p_{h} / p_{l}-1}{p_{h} R-1} W
$$

then if $F \leq F^{*}, \overline{U^{B}}=\underline{U^{B}}=\left(p_{h} R-1\right) F$. Thus, E can appropriate the entire rent to the project by financing from $\mathrm{B}$. On the other hand, $\overline{U^{V C}}<\left(p_{h} R-1\right) F$ because $U^{V C}=q\left(p_{h} R-1\right) F$ and $0 \leq q<1$. As a result, if $F \leq F^{*}$, both $\bar{I}$ and $\underline{I}$ are equal to one. (That is, E finances from B.)

Now suppose that $F>F^{*}$, then

$$
\overline{U_{B}} \equiv \frac{\alpha p_{h} \Phi}{\bar{p}}+\left(\frac{p_{h}}{\bar{p}}-1\right) W
$$

and

$$
\underline{U_{B}} \equiv \frac{(1-\alpha) p_{h} \Phi}{\hat{p}}+\left(\frac{p_{h}}{\hat{p}}-1\right) W
$$

Since both $\overline{U^{B}}$ and $U^{V C}$ are linear in $F$, there is at most one value of $F$ such that $U^{V C}=\overline{U^{B}}$. Similarly there is at most one value of $F$ such that $U^{V C}=\underline{U^{B}}$. Together with the observation that $\overline{U^{B}}=\underline{U^{B}}>U^{V C}$ when $F \leq F^{*}$, the proposition follows.

Figure 5 illustrates how E's payoff changes in $F$. If $F \leq W$, E can finance the project by issuing a risk-free debt. If $W<F \leq F^{*}$, E can still appropriate all return to the project by financing from $\mathrm{B}$ since the asymmetric information problem is completely circumvented through B's threat to seize E's collateral. If $F>F^{*}$, the asymmetric information becomes costly enough such that B has to bribe unprofitable $\mathrm{E}$ by a positive transfer, $T$ in order to screen profitable projects from unprofitable one. This is costly to profitable $\mathrm{E}$ because $\mathrm{B}$ demands a high rate of interest to compensate the expected loss in case E turns out 


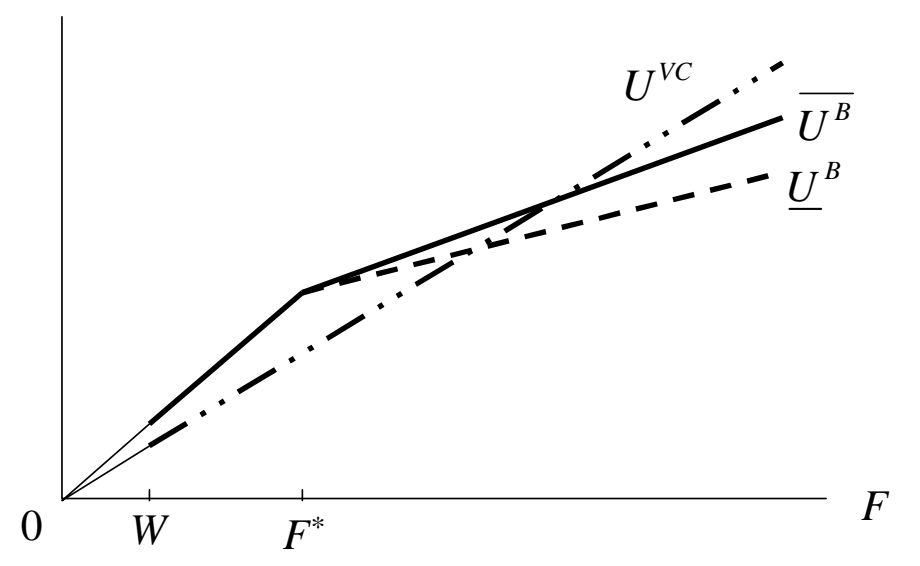

Figure 6:

unprofitable. For this reason, both $\overline{U^{B}}$ and $\underline{U^{B}}$ are truncated at $F=F^{*}$. On the other hand, free from the asymmetric information problem, $U^{V C}$ is linear in $F$ everywhere and strictly smaller than $\overline{U^{B}}$ and $\underline{U^{B}}$ if $F$ is small enough.

Intuition behind this corollary is similar to the one behind Corollary 1 . When E has a large project, its return is high if the project is successful. This return to the success is so attractive to unprofitable $\mathrm{E}$ that the asymmetric information problem becomes severe. And if a large scale project may worsen this problem more drastically than the expropriation problem may, - to be more concrete, if there occurs the coexistence of financing sources: a small project goes to a bank and a large project goes to a venture capitalist. This situation is likely to happen when $q$ is high but less than one.

\subsection{High-rate of return project goes to VC.}

Keeping to assume that $L=q \Phi \equiv q\left(p_{h} R-1\right) F$, the model also implies that $\mathrm{E}$ tends to finance from $\mathrm{VC}$ if the rate return to the project is high:

Corollary 4 Both $\bar{I}$ and $\underline{I}$ are non-increasing in $R$. That is, E finances from $V C$ if the E's project has a high rate of return and from $B$ if it has a low rate of return. 
Proof: Similar to the proof of Corollary 3.

Note that since the expected profit, $\left(p_{h} R-1\right) F$ is increasing in both $R$ and $F$. Corollaries 2 and 3 suggest that $\mathrm{E}$ with a high profitability project tends to go to VC.

\section{5 "High-tech" entrepreneur goes to VC?}

One common notion about venture capital is that high-tech firms often raise funds from venture capital. In the present model, "high-tech" is associated with low $\alpha$. Because understanding high-tech firms requires expertise in the areas of the technology that the firms hold, venture capital presumably has a strong advantage in evaluating the projects relative to commercial banks. Thus, $\alpha$ is likely to be low. An interesting question is then how $\alpha$, affects the choice of the financing source in the model. This case is not as simple as the comparative statics presented above since an decrease in $\alpha$ disfavors profitable $\mathrm{E}$ if she has the good signal while favors her if she has the bad signal. To be concrete, $\overline{U^{B}}$ is increasing in $\alpha$ while $\overline{U^{B}}$ is decreasing in $\alpha$. When $\alpha$ is low and B evaluates the project less accurately, B regards the good signal as a weaker sign that $\mathrm{E}$ is very much likely profitable type while the bad signal implies that $\mathrm{E}$ is more likely profitable. Thus, when B sees the good signal, B charges a higher rate of interest in order to compensate a high expected loss from dealing with unprofitable E. When B sees the bad signal, B can offer a lower rate of interest expecting that $\mathrm{E}$ is more possibly profitable type. For this reason, a lower $\alpha$ and the resulting weaker accuracy of the signal moves profitable $\mathrm{E}$ with the good signal towards $\mathrm{VC}$ while one with the bad signal towards B. As a result of these opposite effects, the model does not give a unambiguous result that arises from changes in $\alpha$.

\section{Discussion}

In this section, I discuss the assumptions and the results of the model. 


\subsection{Weak Protection of Intellectual Property Rights}

One of the crucial assumptions in the model is the weak of intellectual property rights. If they are well protected, the entrepreneur is free from the expropriation threat, and can always obtain the whole rent from the project by asking $\mathrm{VC}$ for funds. In reality, protection of intellectual property rights seems to be weak as assumed in the model. The property rights to an idea are at most partial even if the entrepreneur patents the idea. For instance, Mansfield, Schwartz, and Wagners' survey (1981) shows that imitations of patented goods often occur. Levin, Klevorick, Nelson, and Winter (1987) and Cohen, Nelson, and Walsh (1997) find in their survey dataset that the most important way to secure the return to an innovation is to maximize lead-time and patent is not playing a substantial role in protecting intellectual property rights on average.

\subsection{Can contracts prevent the expropriation?}

The discussion above argues that the legal system is not complete in protecting intellectual property rights. Can a contractual arrangement instead of the legal system circumvent expropriation of intellectual property rights? Putting this question into the context of the current paper, can E and VC write a contract such that $\mathrm{VC}$ must pay an amount of penalty for expropriation beyond the stipulated amount of the legal penalty. I implicitly omit this possibility when describing the model. and now justify this omission by a difficulty with selling information. Unlike selling goods and other services, selling information requires the seller of the information not to reveal its contents to the buyer of the information. This is because revealing its contents already makes it possible that without paying the buyer uses the information in the absence of the complete protection of intellectual property rights. On the other hand, if the seller tries to hide the contents of the information, the buyer is not willing to pay for such information as its content may turn out useless for the buyer. This difficulty with selling information presumably prevents $\mathrm{E}$ and $\mathrm{VC}$ to write a 
contract to impose a huge penalty to the expropriation.

There are two timings when E and VC can possibly write such a contract. The one is after E reveals the contents of the project to VC. Similar to the argument above, $\mathrm{VC}$ has already acquired the content of the project and can use this information without paying to $\mathrm{E}$. Thus $\mathrm{VC}$ prefers not to agree to such a contract. The other timing for writing such a contract is before $\mathrm{E}$ reveals the contents of the project to VC. Nonetheless, VC has not yet known the content of the project and what the parties can do most is to write a contract such that VC must pay a huge penalty to $\mathrm{E}$ in case $\mathrm{VC}$ will infringe any of E's intellectual property. Similar to the argument above, VC presumably prefers not to write such a contract owning to asymmetric information problems. Without knowing what E knows, committing not to use the same ideas as E's knowledge reduces VC's flexibility since VC has to limit its scope of projects to the areas which E is not knowledgeable and should not have figured out the same projects.

\subsection{Why Does B not Consult VC?}

$\mathrm{B}$ may be able to avoid making mistakes in assessing the project by hiring $\mathrm{VC}$ for just evaluating E's project. E, however, would not want to disclose the project to $\mathrm{B}$ in this case because $\mathrm{B}$ would be able to require a high return to lending by threatening $\mathrm{E}$ with having $\mathrm{VC}$ copy the project. A lack of expertise may be B's advantage since B can commit not to imitate E's idea.

\subsection{Does a bank offer a menu of contracts in reality?}

I assumed that B offers a menu of contracts to distinguish the quality of entrepreneurs. How does B do this in practice? Although banks do not seem to offer menus of contracts explicitly (unlike insurance companies), other elaborate financial arrangements may overcome the adverse selection problem. For instance, commercial banks sometimes offer favorable terms for large sums of deposits. This may work to screen a unprofitable entrepreneur since such an entrepreneur must prefer a high safe return to a risky contract which is meant 
to attract profitable entrepreneurs. Staging of finance may also function as a screening device: B may initially lend a part of the total funds required at a low rate of interest and later the rest of the funds at a high rate of interest. Profitable entrepreneur will be confident enough of accomplishing the project to borrow the full amount required whereas unprofitable entrepreneur will not want to borrow at the later stage.

Furthermore, suppose that B offers a single rate of interest like in the way that many banking literature assumes. (For instance, Stiglitz and Weiss, 1981, and De Meza and Webb, 1987) All corollaries presented above are robust to this change of assumption. To see this point, consider the model in which B offers a single interest rate, $r$, to E rather than a menu of contract. This loan contract specifies that B seizes a whole amount of $W$, from $\mathrm{E}$ if the project returns zero, and $\mathrm{E}$ pays $(1+r) F$ to $\mathrm{B}$ if the project returns $R F$. Under this loan contract, profitable E's expected payoff is $p_{h}(R F-(1+r) F)-\left(1-p_{h}\right) W$. If there were no possibility for $\mathrm{E}$ to turn to $\mathrm{VC}$, the zero profit condition of $\mathrm{B}$ determines the interest rate as follows:

$$
\begin{aligned}
\bar{p}(1+r) F+(1-\bar{p}) W & =F \text { if } s=\bar{s} \text { and } \\
\underline{p}(1+r) F+(1-\underline{p}) W & =F \text { if } s=\underline{s} .
\end{aligned}
$$

These conditions implies that profitable E's expected payoff is

$$
\begin{aligned}
& p_{h}\left(R-\frac{1}{\bar{p}}\right) F+\left(\frac{p_{h}}{\bar{p}}-1\right) W \text { if } s=\bar{s} \text { and } \\
& p_{h}\left(R-\frac{1}{\underline{p}}\right) F+\left(\frac{p_{h}}{\underline{p}}-1\right) W \text { if } s=\underline{s} .
\end{aligned}
$$

These payoffs are very similar to $\overline{U^{B}}$ and $\underline{U^{B}}$ : linear and increasing in $R, F$ and $W$. Thus, all corollaries proved in the original model remain unchanged even restricting $\mathrm{B}$ to offering a single interest rate to $\mathrm{E}$.

The difference between the two model is found in what B can do. In the original model, B can offer more than one of contracts. This flexibility leads to the investment efficiency such that profitable $\mathrm{E}$ invests while unprofitable $\mathrm{E}$ 
does not On the other hand, restricting B to offer a single loan contract yields the investment inefficiency. This fact has already been found by Bester (1986) and De Meza and Webb (1987). In the Bester's model, there is no investment inefficiency while there is over investment in De Meza and Webb.

\subsection{Timing}

In this paper, I assumed that $\mathrm{E}$ first negotiates with $\mathrm{B}$ and only if the bargaining between $\mathrm{E}$ and $\mathrm{B}$ fails $\mathrm{E}$ negotiates with $\mathrm{VC}$. What if $\mathrm{E}$ can choose either B or VC to negotiate with first? The model, as it is, then has multiple equilibria. In addition to the equilibrium financing source under the original timing assumption, there are equilibria in which $\mathrm{VC}$ finances richer types of $\mathrm{E}$ than the ones under the original timing assumption. This is because belief is self enforcing. If B believes that profitable entrepreneur finances from $\mathrm{VC}$, then only unprofitable $\mathrm{E}$ comes to negotiate with $\mathrm{B}$. As a consequence, $\mathrm{B}$ does not offer an attractive term of contracts to such a $\mathrm{E}$ and then this belief induces profitable $\mathrm{E}$ to negotiate with $\mathrm{VC}$ first.

Nonetheless, introducing a small bounded rationality of B, this kind of equilibria do not survive and the equilibrium under the original timing assumption only survives. Suppose that even with a very small probability, B may give a term of contract that is better than the one that $\mathrm{VC}$ would offer. $\mathrm{E}$ then always chooses to negotiate with B first because disclosing the project to B does not invite a threat of expropriation and is costless. Knowing that profitable $\mathrm{E}$ negotiates with B first, the timing is much like in the one in the original model. In this way, a small bounded rationality induces any types of profitable $\mathrm{E}$ to negotiate with B first. Hence, the timing assumption in the model is robust to allowing $\mathrm{E}$ to choose the sequence of the negotiation.

\subsection{Bargaining Power of VC}

In the model presented above, I assumed that $\mathrm{E}$ has all bargaining power when negotiating with $\mathrm{VC}$. The model can be easily extended to the case in which 
VC also has some bargaining power. In this case, E's payoff under the VC financing becomes smaller and a richer type of E finances from B. Nonetheless, all qualitative results presented above remain unchanged.

\section{Conclusion}

In this paper, I studied the choice of financing sources when venture capital can assess an entrepreneur's idea better than banks can. Although this assessment advantage makes financing from $\mathrm{VC}$ attractive, such financing entails the cost of revealing the technological information and inviting the threat of expropriation by VC. When an entrepreneur finances from the bank, she has to incur a signaling cost due to the bank's poorer assessment skill but can avoid the threat of expropriation. The choice between bank and VC depends on the two elements: the one is how severe the asymmetric information problem between the entrepreneur and the bank is and the other is how strongly intellectual property rights are protected. Low collateral, high growth, and high return to the project all worsen the asymmetric information problem and thereby the entrepreneur tends to finance from VC. Stronger protection of intellectual property rights weakens the threat that VC may expropriates the entrepreneur's project and thereby the entrepreneur tends to finance from VC. These implications of the model are consistent to the stylized feature of venture-backed firms and the recent dramatic growth of the venture capital industry.

Although the paper focuses on the comparisons between $\mathrm{VC}$ and banks, the model also applies to various financiers that are different in their degree of technological expertise. ${ }^{11}$ What I call VC in the model can be business angels and/or corporations because they are on-going users of technology and their familiarity possibly helps them screen as well as expropriate projects.

\footnotetext{
${ }^{11}$ Leshchinskii (2000) differentiates business angels and VC by assuming that business angel is wealth constrained on the one hand, $\mathrm{VC}$ is not on the other. As a consequence, $\mathrm{VC}$ can invest in a large portfolio of firms and become tough in shutting down one or many ventures in the portfolio.
} 


\section{References}

[1] Admati, A., and P. Pfleiderer, 1994, "Robust Financial Contracting and the Role of Venture Capitalists," Journal of Finance 49(2), 371-402.

[2] Anand, B., and A. Galetovic, 1998, "Weak Property Rights and Hold-up in R \& D," Journal of Economics and Management Strategy, .forthcoming.

[3] Anton, J.J., and Yao, D.A., 1994, "Expropriation and inventions: Appropriable rents in the absence of property rights." American Economic Review 84(1), 190-209.

[4] Bergemann, D. and U. Hege, 1998, "Venture Capital Financing, Moral Hazard, and Learning," Journal of Banking \& Finance 22 (6-8), 703-35.

[5] Berger, A.N., and G.F. Udell, 1998, "The Economics of Small Business Finance: The Roles of Private Equity and Debt Markets in the Financial Growth Cycle," Journal of Banking and Finance 22.

[6] Berglof, E., 1994, "A Control Theory of Venture Capital Finance," Journal of Law, Economics and Organization 10(2), 247-26\%.

[7] Bester, H., 1985, "Screening vs. Rationing in Credit Markets with Imperfect Information," American Economic Review 75 (4), 850-55.

[8] Bhattacharya, S., and Ritter, J., 1983, "Innovation and Communication: Signaling with partial disclosure." Review of Economic Studies 50, 331-346.

[9] Chan Y., 1983, "On the Positive Role of Financial Intermediation in Allocations of Venture Capital in a Market with Imperfect Information," Journal of Finance, 1543-1561.

[10] Cohen, W.M., R.R. Nelson, and J.Walsh, 1997, "Appropriability Conditions and Why Firms Patent and Why They Do Not in the American Manufacturing Sector," unpublished manuscript.

[11] Cornelli, F. and O. Yosha, 1997, "Stage Financing and the Role of Convertible Debt" CEPR Discussion Paper 1735.

[12] Dessi, R., 1999, "Financing Entrepreneurs: Optimal Contracts and the Role of Intermediaries," mimeo, IDEI, Toulouse. 
[13] De Meza, D., and D. Webb, 1987, "Too Much Investment: A Problem of Asymmetric Information," Quarterly Journal of Economics 102(2), 281-92.

[14] Feeney, L.S., G. Haines, Jr., and A.L. Riding, 1998, "SME Owners' Awareness and Acceptance of Equity Capital: Implications for Lenders," Carlton University.

[15] Fenn, G.W., Liang, N., and Prowse, S., 1996, "The Economics of the Private Equity Market." Board of Governors of the Federal Reserve System Stuff Study 168.

[16] Gompers, P., 1995, "Optimal Investment, Monitoring, and the Staging of Venture Capital" Journal of Finance 50(5), 1461-1489.

[17] Gompers, P., 1997, "Ownership and Control in Entrepreneurial Firms" An Examination of Convertible Securities in Venture Capital," mimeo, Harvard Business School.

[18] Gorman, M. and Sahlman, W., 1989, "What do venture capitalist do?" Journal of Business Venturing 4, 231-248.

[19] Hellmann, T., 1998, "The Allocation of Control Rights in Venture Capital Contracts," Rand Journal of Economics 29(1), 57-76.

[20] Hellmann, T., and M. Puri, 2000, "The Interaction between Product Market and Financing Strategy: The Role of Venture Capital" forthcoming in Review of Financial Studies.

[21] Hellmann, T., and M. Puri, 1999, "Venture Capital and the Professionalization of Start-ups: Empirical Evidence" mimeo, Stanford University.

[22] Holmstrom, B., and J. Tirole, 1997, "Financial Intermediation, Loanable Funds, and the Real Sector," Quarterly Journal of Economics 112(3), 66391.

[23] Kaplan, S., and P. Stromberg, 1999, "Financial Contracting Meets the Real World: An Empirical Study of Venture Capital Contracts," Working paper, University of Chicago.

[24] Kirilenko, A.A., 2001, "Control and Valuation in Venture Finance," Journal of Finance, forthcoming. 
[25] Leshchinskii, D., 2000, "Venture capitalists as benevolent vultures: The role of network", HEC.

[26] Levin, R.C., Klevorick, A.K., Nelson, R.R., and Winter, S.G, 1987, "Appropriating the Returns from Industrial Research and Development." Brookings Papers on Economic Activity, 3, 783- 831.

[27] Merges, R.P., 1992, Patent Law and Policy. Charlottesville: Michie Company.

[28] Repullo, R., and J. Suarez, 1998, "Venture Capital Finance: A Security Design Approach," mimeo, CEMFI, Madrid.

[29] Rothschild, M., and Stiglitz, J., 1976, "Equilibrium in Competitive Insurance Markets: An Essay on the Economics of Imperfect Information." Quarterly Journal of Economics, 82, 629-49.

[30] Sahlman, W.A., 1990, "The structure and governance of venture-capital organizations," Journal of Financial Economics 27(2), 473-521.

[31] Schmidt, K.M., 2000, "Convertible Securities and Venture Capital Finance," http://www.vwl.uni-muenchen.de/ls_schmidt/index.html.

[32] Stiglitz, J.E., and A. Weiss, 1981, "Credit Rationing in Markets with Imperfect Information," American Economic Review 71(3), 393-410.

[33] Ueda, M. 1997, "Expertise and Finance: Mergers Motivated by Technological Change," UPF working paper.

[34] Yosha, O., 1995, "Information Disclosure Costs and the Choice of Financing Source," Journal of Financial Intermediation 4(1), 3-20. 